\title{
BRECHT, Martin, DEPPERMANN, Klaus, Geschichte des Pietismus, t.2: Der Pietismus im 18. Jahrhundert
}

Patrice Veit

\section{OpenEdition}

\section{Journals}

Édition électronique

URL : http://journals.openedition.org/ifha/1919

DOI : 10.4000/ifha.1919

ISSN : 2198-8943

Éditeur

IFRA - Institut franco-allemand (sciences historiques et sociales)

Référence électronique

Patrice Veit, «BRECHT, Martin, DEPPERMANN, Klaus, Geschichte des Pietismus, t.2: Der Pietismus im 18. Jahrhundert », Revue de l'IFHA [En ligne], Date de recension, mis en ligne le 01 janvier 1995, consulté le 22 septembre 2020. URL : http://journals.openedition.org/ifha/1919; DOI : https://doi.org/10.4000/ ifha.1919

Ce document a été généré automatiquement le 22 septembre 2020.

(C)IFHA 


\title{
BRECHT, Martin, DEPPERMANN, Klaus, Geschichte des Pietismus, t.2: Der Pietismus im 18. Jahrhundert
}

\author{
Patrice Veit
}

1 Avec ces deux volumes consacrés, l'un, à la période s'étendant du XVIIe au début du XVIIIe s., l'autre, au XVIIIe s., est inaugurée une nouvelle Histoire du piétisme, prévue en 4 volumes et placée sous l'égide de la Historische Kommission zur Erforschung des Pietismus (depuis 1974 éditeur, par ailleurs, du volume annuel Pietismus und Neuzeit. Ein Jahrbuch zur Geschichte des neueren Protestantismus, Göttingen, et aussi de la collection Arbeiten zur Geschichte des Pietismus). Cette entreprise de taille constitue la première grande synthèse, depuis les trois volumes d'Albert Ritschl au siècle dernier (1880-1886), sur ce mode de pensée religieux lié également à une pratique sociale, qui attend toujours, mis à part la thèse de J.B. Neveux (Vie spirituelle et vie sociale entre Rhin et Baltique au XVIIe siècle, de J. Arndt à P.J. Spener, Paris, 1967) une présentation en langue française à la mesure de son importance historique.

2 L'intérêt du premier volume dirigé par l'historien de l'Eglise M.B., auteur par ailleurs d'une monumentale biographie de Luther (voir BullMHFA 16, juin 1988, p.117), et qui a rédigé les chapitres consacrés à l'Allemagne, est de donner une vision élargie du piétisme aussi bien chronologiquement que géographiquement. Si le terme "piétisme» fait son apparition en Allemagne surtout à la fin du XVIIe s., l'ouvrage situe, en effet, le terminus ante quem de ce courant dès le début du XVIIe s. dans les mouvements spirituels qui affectent le protestantisme et qui trouvent des parallèles en Angleterre et aux Pays-Bas. Deux chapitres substantiels sont consacrés en début de volume au puritanisme anglais et aux différents courants religieux dans le protestantisme des Pays-Bas marqués par les personnalités de Gisbertus Voetius, de Theodirus à Brakel ou du Français Jean de Labadie. Ainsi replacés, ils permettent de mieux apprécier les influences qu'ils ont jouées sur le renouveau spirituel que connaît le luthéranisme dans l'Allemagne de la première moitié du XVIIe s., longtemps considérée trop exclusivement comme une période d'orthodoxie religieuse. Ce renouveau se traduit 
notamment par un essor sans précédent de la littérature de dévotion (Johann Arndt et les Vier Bücher vom Wahren Christentum, par exemple) et du cantique (Johann Heermann ou Paul Gerhardt). Les différents autres chapitres sont respectivement consacrés aux spiritualistes allemands du XVIIe s. au premier rang desquels Jacob Böhme, au piétisme réformé allemand autour principalement de Joachim Neander ainsi qu'au piétisme radical caractérisé par ses tendances eschatologiques. Les contributions les plus importantes concernent les deux grands protagonistes du piétisme, leur œuvre et leur rayonnement: Philipp Jakob Spener, dont les Pia desideria (1675) fondent traditionnellement le mouvement, et August Hermann Francke, élève du précédent, dont les institutions d'assistance et d'éducation (les fameuses Franckeschen Stiftungen, tout récemment restaurées et appelées à servir de centre culturel international à vocation pédagogique, scientifique et de recherche - Die Zeit, n 43, 20 octobre 1995, p. 58) ont assuré la diffusion du piétisme en Allemagne et au-delà.

3 L'originalité du second volume, consacré au XVIIIe s. c'est-à-dire à l'époque de véritable expansion du piétisme, réside en ce qu'il présente pour la première fois une synthèse complète sur l'implantation et sur l'évolution du piétisme dans les différentes régions et les différents pays. Cela ne veut pas dire que soient pour autant négligés les nouveaux courants spirituels apparaissant au XVIIIe s., comme la communauté des Herrnhuter, les frères moraves, marquée par la personnalité du comte Nikolaus Ludwig von Zinzendorf (1700-1760), ou les tendances très variées du piétisme radical autour notamment de personnalités comme les époux Petersen ou Gottfried Arnold, courants qui, aux côtés du piétisme de Spener et de Halle, vont avoir une influence dans de nombreux endroits. La succession d'études régionales proposées dans le volume permet d'apprécier l'impact très divers du piétisme selon les régions, que ce soit dans la durée du phénomène, dans ses formes ou dans ses conséquences religieuses, spirituelles et sociales: certaines contrées sont profondément touchées, développant des caractéristiques propres - tel est le cas du Wurtemberg sous l'influence notamment de Johann Albrecht Bengel (1687-1752) ou du Brandebourg et de la Prusse où se répand le piétisme inspiré de Halle - tandis que dans d'autres régions, comme en Hesse ou en Alsace, le mouvement reste assez minoritaire. Le piétisme réformé des régions basrhénanes, de Hollande et des Cantons Suisses manifeste un certain nombre de traits communs et des influences réciproques. La conception de l'ouvrage est largement européenne, puisque plusieurs chapitres sont également consacrés au piétisme au Danemark et dans les pays scandinaves et que le volume s'achève par une importante présentation du méthodisme anglais et par celle du puritanisme et du piétisme nordaméricain dans ses différentes phases et ses particularismes.

4 Moins traditionnel que le premier volume un peu trop enfermé dans une conception essentiellement théologique, le second tome est un précieux outil et comble véritablement une lacune à travers le panorama qu'il propose. Si l'on pourra regretter que les aspects sociaux ne soient pas davantage pris en considération - n'est-ce pas d'ailleurs un manque plus général concernant les recherches sur le piétisme? -, le sérieux et la qualité de la présentation qui prend en compte les travaux les plus récents mentionnés en tête de chaque chapitre, font attendre avec intérêt les prochains volumes de cette nouvelle histoire du piétisme consacrés aux prolongements aux XIXe et XXe s. (III) comme à ses influences religieuses, culturelles et artistiques (IV). 